\title{
Social Exchange Between a DMO and Its Stakeholders: A Case Study in the Rural Southeast United States
}

\author{
Angela G. Sebby, $\mathrm{PhD}$ \\ CHE, CHIA \\ Hospitality \& Tourism Program, College of Business \\ Western Carolina University, Cullowhee, NC 28723, USA \\ E-mail: agsebby@wcu.edu
}

Received: Nov. 23, 2018 Accepted: December 15, 2018 Published: December 22, 2018

doi:10.5296/csbm.v5i2.13958 URL: http://dx.doi.org/10.5296/csbm.v5i2.13958

\begin{abstract}
Many rural areas in the Southeastern United States implement tourism to supplement the declining manufacturing and farming opportunities in their communities. Through informative resources from the USDA, regional tourism development projects, the Main Street America program, and national, state, and regional grants, rural communities have the necessary building blocks readily available to advance tourism projects. However, numerous rural counties still incur obstacles in the development of tourism, resulting in the inability for them to sustain a viable destination area.

Destination Marketing Organizations (DMOs) appear ineffective in marketing the rural area as a destination that fully embodies the culture, history, and natural resources it exhibits due to small-town politics, naivety of the benefits of tourism, and misaligned brand images. Consequently, visitor demands and expectations cannot be met due to the lack of trust in the DMO's ability to recognize the stakeholders' contributions for the betterment of the community as a destination brand.

Understanding how to obtain stakeholders' confidence, a DMO can develop strategic relationships through continual and consistent social exchange, strengthened over time, as trust evolves. These relationships sustain the all-inclusive brand image for the rural destination area, increasing visitor satisfaction and, therefore, stakeholder investments.
\end{abstract}

Keywords: rural, tourism, social exchange, trust, destination marketing organization 


\section{Introduction}

Marketing a tourism destination area while managing the resources available is the responsibility of the Destination Marketing Organization (DMO). DMOs are a not-for-profit organization responsible for developing a brand image for the area, generating tourism interest, providing information to visitors and meeting/event planners, and coordinating services and information between tourism industry business partners (Prideaux \& Cooper, 2002). According to the United Nations World Tourism Organization (2018), DMOs provide the framework for tourism development and policy, marketing, value chain analysis, local economic development, and public-private strategic alliances. In rural localities, this organization may be a Chamber of Commerce or a Convention and Visitor Bureau managing allocated funding to create and maintain a brand image for the tourism area. Embodying the culture, history, and attributes of the area through marketing activities-depicted in photos, words, and logos-a tourism brand image is designed to reflect a distinctive identity and to create a competitive advantage for the destination area and its stakeholders $(\mathrm{Qu}, \mathrm{Kim}, \& \mathrm{Im}$, 2011; Blain, Levy, \& Ritchie, 2005)

In rural areas, stakeholders are comprised of hospitality, restaurant, and tourism business owners, government officials, community participants, and visitors. Invested in the community, the diverse demographics of the stakeholders can hinder the DMO's strategic campaigns. Government tensions, political schedules, and dissimilar interests of the residents can affect stakeholders' support, physically and financially (Sheehan, Ritchie, \& Hudson, 2007).

A viable social exchange model between the DMO and its stakeholders can guide DMOs in formulating strategies that strengthen the alliances to attain visitor satisfaction resulting in a sustainable destination area. To identify stakeholders' positions on the DMO's trustworthiness in developing tourism for the rural area, this entails the further study of the Social Exchange Theory. This theory addresses organizational-stakeholder relationships and relationship marketing.

\section{Literature Review}

DMOs are representatives for tourism businesses, providing prospective visitors information regarding accommodations, attractions, dining options, and logistics. Likewise, DMOs supply local businesses with tourism data-trends, demographics, economic impact, tax revenues-gathered from prospective and repeat visitors (DMAI, 2018; Yuan, Gretzel, \& Fesenmaier, 2006). These businesses-destination area stakeholders-have a vested interest in the development, implementation, success, and sustainability of a rural destination area.

DMOs continually contend with financial insecurity due to government politics, budgets, and constraints and the inexpert perception of the DMO's role and its impact economically on the destination area. Due to the government's naivety of the DMO's activities, area governments have been known to limit or decrease funding for tourism marketing with the intention of increasing support to non-tourism financial agendas (Arbogast, Deng, \& Maumbe, 2017; Gretzel, Fesenmaier, Formica, \& O’Leary, 2006). Diverse goals and tense relations, trust in 
the DMO weakens, resulting in an inefficient organization. For sustainable rural tourism, stakeholders must rely on one marketing entity to fully embody the destination's brand image, while recognizing individual stakeholder contributions to the promotion of the destination area.

Committed to tourism sustainability, DMOs cultivate alliances through community support on the mission, vision, and strategic plans that safeguard the stakeholders' interests while providing innovative ways to market tourists (Wang, 2008; Prideaux, et al., 2003). Leitch and Richardson (2003) explain that these working relationships should be compatible in goals and strategies. This compatibility aids in cultivating trust, cooperation, and commitment (Zineldin, 2004). As trust develops and commitment to the relationship ensues, the tangible and intangible benefits to the stakeholders and the community are strengthened (Cullen, Johnson, and Sakono, 2000).

How successfully the DMO can produce the stakeholders' intended results is based on the stakeholders' trust in the DMO and its effects on the strategic alliance. Exchanging resources to pursue marketing initiatives and strategically managing the rural destination area creates alliances that provide sustainability for the projects. A core definition of social exchange is "an exchange of activity, tangible or intangible, and more or less rewarding or costly, between at least two persons" (Blau, 1964, p. 88). When social exchanges transpire, a perceived commitment to counter in ways that are advantageous to the organization ensues. Trust, however, is required to commence the exchange (Bryne, Pitts, Chiaburu, \& Stiner, 2010).

With trust, DMOs' can utilize relationship marketing to create sustainable and profitable relationships with the stakeholders, cultivating stronger ties, trust, and support. Morgan and Hunt (1994) indicate relationship marketing creates a network of value by encompassing all marketing functions focused on "establishing, developing, and maintaining successful relational exchanges" (p. 22). Building on this, Lusch and Vargo (2014) state multiple connections and affiliations are needed to sustain this value grid. The authors propose that shared values, communication, and opportunities are key mediating variables in relationship marketing. Additionally, according to Yuan et al. (2004) to increase tourism and sustain a viable tourism area, timely interaction with meeting planners and tourists is crucial to the perceived trustworthiness of the DMO.

Relationships are the key drivers for social exchange with trust forming the basis for the relationships (Colquitt, Baer, Long, \& Halvorsen-Ganepola, 2014; Coyle-Shapiro \& Shore. 2007). Introducing vulnerability as the root source for trust, Mayer, Davis, and Schoorman (1995) established that for a constructive social exchange between the DMO and the rural stakeholders to exist, "willingness of one exchange partner to be vulnerable to the actions of another, based on the expectation that the other will perform some action in the absence of monitoring or control" must be evident (p. 712). Expanding upon this theory, high levels of support and integrity in social exchanges will create higher levels of trust and organizational citizenship behaviors (Cropanzano, Daniels, Anthony, \& Hall, 2017). Supporting each other, strengthening relationships, and advocating for the benefits of tourism through positive social exchanges, DMOs and stakeholders can meet the demands and expectations of the visitor as 
defined by the brand image, thereby increasing visitor satisfaction and revisit intentions.

\section{Methodology}

Focused in a rural Tennessee area known for successful tourism efforts, the county chosen for the study was a registered National Historic District. With the population growth of $35 \%$ over the past 20 years, this town is home to approximately 3000 residents. The area has been transformed from a small, quaint town into one that has grown substantially over the past few years. It encompasses the culture of the historic area while incorporating more dining locations, small-town businesses, and numerous events throughout the year. With predominately diverse natural water attractions located within the county, the site also emphasizes historical sites to encourage heritage tourism. This case study addressed the following research questions in this rural community: 1) Forming strategic alliances with stakeholders has produced what perceived benefits? And 2) when using these alliances, what is the perception of the DMO's effectiveness?

By utilizing grounded theory to examine the social exchanges and relationships between the DMO and stakeholders in the rural area, it allowed for the DMO and EDA to reflect on personal experiences and informal relations pertinent to the development of tourism. Grounded theory also allowed for researcher memos, constant comparative analysis, and intermediate coding to identify obscure themes and categories. Based on a constructivist paradigm using an explanatory theoretical framework, this methodology describes the importance of cultures, social circles, and individuals (Hatch, 2002). Also influenced by social constructivism, grounded theory in this study reflected that knowledge is shaped by our experiences and that individuals "understand the world from their own vantage points" (Hatch, 2002, p. 15).

A monthly tourism planning meeting site was selected for observation and to develop the interview protocol. In attendance were the county mayor, aldermen, department heads, town administrators, the staff of the Chamber of Commerce, the Director of Tourism, and local and regional tourism industry professionals. Through observation of verbal and non-verbal interactions during this meeting, it was determined the Director of the Chamber of Commerce and the Director of the Economic Development Agency were directly responsible in cultivating stakeholder relationships vital to tourism development. Two topic domains were then crafted to address the perceived benefits of stakeholders and the effectiveness of the DMO's strategic alliances.

A criterion sampling strategy with purposeful sampling was employed. Both interviewees were involved in the development of the county and city with numerous years of experience in the tourism and economic development industry. The interviews were conducted using an informal, unstructured, and open-ended (Polkinghorne, 1989) style to bring out the participants' feelings and thoughts on their work (Fetterman, 1998). The first interview was conducted with the county's Director of Tourism. She was the county's first Tourism Director and had held the position for five years. College educated in marketing, public relations, she was familiar with the state's tourism programs for the county and optimistic about the tourism growth in the rural area. She was well-versed in tourism planning, networking, and grant 


\section{Macrothink}

application to pursue further economic development to increase tourism. Additionally, the Director was strategic on the goals and objectives for tourism in the county and was proactive about informing the stakeholders on how to proceed to increase it.

Preceding the interview with the tourism director, the interview with the Director of the Economic Development Agency (EDA) was conducted in the same office. The EDA Director did not readily share his qualifications and indicated that although they shared the same office, he was unaware of the Tourism Director's efforts in increasing tourism in the area. Throughout his interview, he concentrated on sharing his endeavors in increasing industries to relocate to the county. His references to tourism were minimal.

A thick description from the observation at the Town Hall tourism meeting, as well as the transcribed interviews with the Director of Tourism and the Director of Economic Development, were utilized during data analysis, without bias or pre-conceived notions. No review of literature was performed beforehand to discourage prevalent knowledge about the topic. Hatch (2002) indicates this allows one the opportunity for discovering additional themes.

Open and axial coding was employed while analyzing and comparing perceptions and relationships, by scrutinizing each line of verbatim text as individual subject matter rather than an entire context. Coding resulted in 123 significant codes relevant to the research design of the study. The information was numbered and presented in chart form (see Table 1). Codes were developed from actual interviewee wording, and while their frequency was not counted, attention was paid to multiple references of similar subject areas. 
Table 1. Examples of high-frequency codes with supporting units of data

\begin{tabular}{|c|c|c|}
\hline Code & Supporting Units of Data & (O =observation, I=Interview) \\
\hline Leverage & $\begin{array}{l}\text { "leverage resources" (I, 3) } \\
\text { "leveraging that piece of it" (I, 8) } \\
\text { "Leaveraging those kinds of relationships" (I, 21) } \\
\text { "leveraging" (I, 23) } \\
\text { "leveraging everything the state already has to } \\
\text { offer..."(I, 29) } \\
\text { "leverage the seets that we already have..."(I, 30) }\end{array}$ & \\
\hline Existing assets & $\begin{array}{l}\text { "existing infrastructure" (I, 4) } \\
\text { "Currently have" (I, 5) } \\
\text { "taking the asset" (I, 7) } \\
\text { "taking the water that is already here" (I, 13) } \\
\text { "the parking that already exists...." (I, 14) } \\
\text { "utilize that" (I, 14) } \\
\text { "assets be better used" (I, 16) } \\
\text { "infrastruce improvements related to tourism" (I, 19) } \\
\text { "natural resources that we have" (I, 3) } \\
\text { "relationships that have been mostly beneficial..." (I, } \\
\text { 25) } \\
\text { "inventory was we have..."(I, 30) }\end{array}$ & $\begin{array}{l}\text { "underdeveloped as far as a lot of infrastructure needs go" } \\
\text { (I, 75) } \\
\text { "state department of tourism already has in place" (I, 87) } \\
\text { "social media that TDT already has in place" (I, 91) } \\
\text { "CMS system" } \\
\text { "your own user name, your own password....website" (I, } \\
\text { 92) } \\
\text { "tools and assets" (I, 93) } \\
\text { "local tourism professionals" (I, 105) } \\
\text { late } 60 \text { 's (o) } \\
\text { CMS system provided by the State of Tennessee Tourism } \\
\text { Dept. (o) }\end{array}$ \\
\hline Deficient & $\begin{array}{l}\text { "hasn't been an infrastructure master plan or } \\
\text { recreational master plan" (I, 64) } \\
\text { "hasn't been a moment when someone has looked } \\
\text { out ten to twenty years" (I, 65) } \\
\text { "hasn't been a plan into taking into account..." (I, } \\
\text { 67) } \\
\text { "tourism is a priority" (I, 68) } \\
\text { "help us understand our infrastructure challenges" (I, } \\
71) \\
\text { "hindrance just the state of the situation that we are } \\
\text { in" (I, 74) }\end{array}$ & $\begin{array}{l}\text { rough gravel parking lot }(\mathrm{O}) \\
\text { windowpanes in need of touchup }(\mathrm{O}) \\
\text { smell of mustiness }(\mathrm{O}) \\
\text { dark hallway (o) } \\
\text { large brown oak pew }(\mathrm{O}) \\
\text { old weathered oak floors squeaked medium lout and very } \\
\text { consistent }(\mathrm{O})\end{array}$ \\
\hline Relationships & $\begin{array}{l}\text { "Building relationships" (I, 6) } \\
\text { "reaching out" (I, 6) } \\
\text { "partnering with" (I, 10) } \\
\text { "recruiting and hosting large-scale" (I,9) } \\
\text { "partner in doing that with us...." (I, 17) } \\
\text { "ask for them...." (I, 18) } \\
\text { "ask for TVA to help you..." (I, 20) } \\
\text { "neighbors...building those relationships" (I, 25) } \\
\text { "partnering and leveraging those kinds of } \\
\text { relationships" (I, 28) } \\
\text { "partner to increase tourism" (I, 32) }\end{array}$ & $\begin{array}{l}\text { chatting, laughing, and greeting others (o) } \\
\text { co-ops }(\mathrm{O})\end{array}$ \\
\hline
\end{tabular}

\section{Results}

Codes were made conceptually congruent while consistently referring to the purpose statement and then connecting them based on aggregation of data with a common idea. This common idea is interpreted to offer explanations of the data and attaches significance to it. Through this process, development of people, places, and things appeared to be a predominant theme that encompassed many of these categories: existing assets, deficiency, 
and education. Relationships as the second theme included leverage, perception, communication, and monetary value (the perception of the actual) as seen in Table 2.

Table 2. Themes and categories derived from codes

\begin{tabular}{ccc}
\hline & $\begin{array}{c}\text { Themes } \\
\text { Development } \\
\text { Relationships }\end{array}$ & \\
\hline Categories/Subcategories & \\
\hline Government & Tourism Industry & Resources \\
& (Natural \& Manmade) \\
Leverage & Leverage & Leverage \\
Existing Assets & Relationships & Defing Assets \\
Relationships & Development & Development \\
Development & Education & \\
Education & Perception & \\
Perception & Communication & \\
Communication & Monetary Value & \\
Monetary Value & & \\
\hline
\end{tabular}

\subsection{Development}

The expansion of existing assets, advancement in tourism educational programs, and deficiencies in the development of tangible tourism resources were considered key drivers in creating a sustainable tourism area for the rural community. It was emphasized during the interviews that it was vital to take existing assets in all three categories (Government, Tourism Industry, Resources), utilize social exchanges to create strategic alliances, and strategically utilize resources together. The Tourism Director referred to natural resources, but also to existing infrastructures and state provided programs as mentioned in the following statements:

"So, taking the water that is already here, the parking that already exists,"

"State Department of Tourism already has in place."

"Access the tools the state already provides."

"Underdeveloped as far as a lot of infrastructure needs go,"

While the resources for a strong foundation have mainly been supplied, the understanding of sustainable tourism practice application is limited as a result of the lack of education indicated by the following statement:

"Educate how to utilize what the state offers."

"Help me understand." 
"Teach me."

"I teach them."

"They're hungry; they're very hungry to learn."

"While the government supplied resources are by no means are these bad tools, they are just a little clunky sometimes."

However, both interviewees noted that without funding, there is a decline in the taxes brought in from tourism, money spent in the destination area, and loss of income for many local industry suppliers. From this deficiency, priority for infrastructure improvements and development will decline. Stating "limited at this point from an infrastructure point of view" and with that limitation comes a decline in tourism "infrastructure that is going to generate tourism," the tourism director indicates an unstable cycle of financial planning and initiatives.

\subsection{Relationships}

This case study revealed that the development of relationships through social exchanges with those in government, in the tourism industry, and those that can maintain existing or create new resources is considered the key driver in development. Strategic alliances affect the perception of tourism in the area, and strong development of the alliances create trust in the social exchange, thereby increasing a positive perception of the DMO and rural tourism initiatives.

Leverage was mentioned numerous times during the interview with the Tourism Director. It was used in the context of all three categories: government, tourism industry, and resources. She emphasized that "For us is to leverage the natural resources that we have and the existing infrastructure. So for us, that is our existing lakes, the parking, and the boat ramps, and the access to the water that we currently have".

Additionally, she referred to leveraging relationships in relation to the government and industry suppliers in the following statements:

"Ask for public authorities to help you understand your land requirements and permits so that you can understand what you can and cannot do on their land from a recreational standpoint. So, I think leveraging those kinds of relationships."

"So, I probably the third part is looking outside of your own community and leveraging relationships with other tourism groups, and regions, and directors, that are your neighbors."

The Tourism Director stated that many stakeholders, including the EDA Director, operated with an erroneous perception of tourism. For many in rural communities, tourism is linked to large attractions and urban areas. Without the attractions, stakeholders were amiss in the monetary benefits to not only the tourism stakeholders but the standard business stakeholders as well. She indicated that utilizing economic multiplier formulas to communicate the benefits of a sustainable rural tourism destination is essential to government and suppliers receiving this information, furthering understanding the amount of money garnered assists in funding tourism programs. Understanding the naivety of stakeholders regarding tourism, she 
stated the following:

"It's really important that there is a perceived value of what tourism does from an economic point of view and what we try to do is monetize as much as we possibly can."

So, for every event, we're trying to communicate to our local media, and to our local government, and to our local investors."

While viewing tourism as important, the EDA Director seemed more concerned with retail and manufacturing. His perception of the monetary benefits of tourism and tourism drivers were limited to retail and restaurants, with little economic development gains projected from each. The EDA Director indicated financial, development, and relationships objectives were progressing and a five-year strategic plan emphasized progressing development. He stated

"The economic/tourism development strategy is funded through a campaign that solicits funds from private and public investors. We are in the second 5-year phase of the effort and recently raised $\$ 2.74$ million from 49 investors - approximately 55\% of funds from the public sector and $45 \%$ from private companies/individuals."

The economic director was objective in his descriptions of past and future results of the combined economic and tourism development strategy. However, it was represented in the following statements there is a lack of communication between economic development and tourism although they share the same small office building.

"As of yet, we have not seen national retailers or local restaurant franchisees interested in locating businesses here to sell to those visitors. Local demographics are still the determining factor for these businesses."

"Personally, I do not have a role in tourism development."

Leveraging resources (relationships, assets, government supplied resources), educating stakeholders, and opening lines of communication are essential for tourism sustainability in rural areas. Communication was one of her dedicated words. The tourism director indicated:

"We're trying to communicate to our local media, and to our local government, and to our local investors."

"That power to communicate themselves,"

"Leveraging communicates the same message."

Monetary value is vital to the success of the DMO, its suppliers, and tourism. The Tourism Director indicated that it is the "monies that may be available for infrastructure" to further develop tourism. However, DMOs constantly have to deal with financial insecurities that is vital to the promotion of tourism in a destination area. Additionally, she stated that

"Tourism monies are an economic development piece is saying that this needs to be more funded." 
"Create funding and grant mechanisms for industries that are creating many, many dollars in the community."

"It also might be nice like with a handout from the state. It's like the seal of approval or the stamp of this is what we believe from a state department tourism is the rule of thumb. Maybe that would carry some authority. Like I said it all looks different. It doesn't look branded from them. It's all there. It's just a refining process."

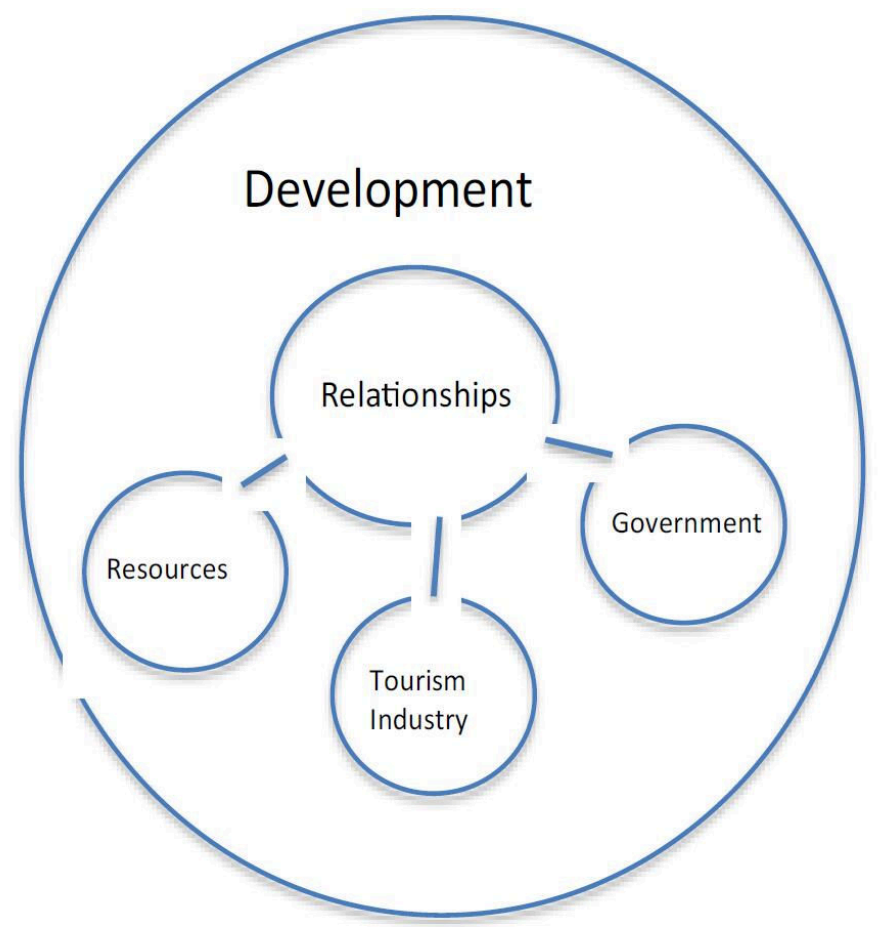

Figure 1. Tentative model illustrating the relationship of themes and categories

\section{Discussion}

Rural stakeholders can provide challenges for developing successful DMO strategies. Knox and Bickerton (2003) express "the ability of all employees, not just marketing departments, to understand and internalize the values embodied in the brand identity is necessary if this is to be transmitted correctly to external stakeholders" (p. 101). Lacking communication between the DMO, the supplier, and the government has resulted in a disjointed brand image.

How appropriately the DMO can create and sustain a holistic brand image for the destination area ultimately affects the entire destination area businesses. Diverse marketing and promotions ultimately affect the destination's competitive position in the tourism market. With multiple images from numerous tourism stakeholders, destination perceptions and evaluations may be altered from the destination brand image. All print advertisements, publicity, direct representation, social media outlets, and supplier relations should be addressed with a consistent destination brand image.

Successful tourism marketing of a destination area involves not only working with meeting planners, conventions, and tourists; it requires relationship building aligned to create a 
consistent destination brand image fulfilling the needs of tourists and stakeholders. Aligning the goals of tourism with the stakeholders establishes the appropriate conditions necessary to increase the trustworthiness of the DMO, thereby gaining more awareness and legitimacy in the destination market. With stronger alliances between the DMO, government, and industry supplier, this information could be readily available in education, resources, and communication.

\section{Conclusion}

With the DMO's emphasis on the key relationships, trust ensues, and a commitment to the relationship is formed. Consequently, this provides exceptional resources, benefits and opportunities, higher standards, and the value of communicating valuable information that could prove to be advantageous to the destination area and the tourists. Therefore, relationship marketing is the DMO's ability to create sustainable and profitable relationships with the stakeholders, and its ability to create stronger ties, trust, and support. In this study, the development of relationships with the government, the tourism industry, and stakeholders who maintain existing or create new resources is vital in forming a sustainable rural tourism destination. Strong development of strategic alliances and relationships will lead to a positive perception of tourism in rural areas, thereby increasing support and assistance from stakeholders.

\section{References}

Arbogast, D., Deng, J., \& Maumbe, K. (2017). DMOs and rural tourism: A stakeholder analysis the case of Tucker County, West Virginia. Sustainability, 9, 1813. https://doi.org/10.3390/su9101813

Blain, C., Levy, S. E., \& Ritchie, J. B. (2005). Destination branding: Insights and practices from destination management organizations. Journal of Travel Research, 43(4), 328-338. https://doi.org/10.1177/0047287505274646

Blau, P. M. (1964). Exchange and power in social life. New York: John Wiley.

Bryne, Z., Pitts, V., Chiaburu, D., \& Stiner, Z. (2010). Managerial trustworthiness and social exchange with the organization. Journal of Managerial Psychology, 26(2), 108-122. https://doi.org/10.1108/02683941111102155

Colquitt, J., Baer, M., Long, D., \& Halvorsen-Ganepola, M. (2014). Scale indicators of social exchange relationships: A comparison of relative content validity. Journal Applied Psychology epub. https://doi.org/10.1037/a0036374

Coyle-Sharpiro, J., \& Shore, L. (2007). The employee-organization relationship: Where do we go from here? Human Resource Management Review, 17(2), 166-179. https://doi.org/10.1016/j.hrmr.2007.03.008

Cropanzano, R., Anthony, E., Daniels, S., \& Hall, A. (2017). Social Exchange Theory: A Critical Review with Theoretical Remedies. The Academy of Management Annals, 11, 1-38. https://doi.org/10.5465/annals.2015.0099 
Cullen, J., Johnson, J., \& Sakono, T. (2000). Success through commitment and trust: The soft side of strategic alliance management. Journal of World Business, 35, 223-240. https://doi.org/10.1016/S1090-9516(00)00036-5

Destinations International. (2018). Retrieved from https://destinationsinternational.org Fetterman, D. M. (1998). Ethnography: Step by step (2nd ed.). Newbury Park, CA: Sage.

Gretzel, U., Fesenmaier, D. R., Formica, S., \& O'Leary, J. T. (2006). Searching for the future: challenges faced by destination marketing organizations. Journal of Travel. https://doi.org/10.1177/0047287506291598

Hatch, J. A. (2002). Doing qualitative research in education settings. Albany, NY: SUNY Press.

Knox, S., \& Bickerton, D. (2003). The six conventions of corporate branding. European Journal of Marketing, 37(7/8), 998-1016. https://doi.org/10.1108/03090560310477636

Leitch, S., \&Richardson, N. (2003). Corporate branding in the new economy. European Journal of Marketing, 37(7/8), 1065-1079. https://doi.org/10.1108/03090560310477663

Lusch, R. F., \& Vargo, S. L. (2014). Service-Dominant Logic: Premises, Perspectives, and Possibilities. Cambridge, UK: Cambridge University Press.

Mayer, R., Davis, J., \& Schoorman, F. (1995). An integrative model of organizational trust. The Academy of Management Review, 20(3), 709-734. https://doi.org/10.5465/amr.1995.9508080335

Morgan, R. M., \& Hunt, S. D. (1994). The commitment-trust theory of relationship marketing. Journal of Marketing, 58(3), 20-38. https://doi.org/10.1177/002224299405800302

Polkinghorne, D. E. (1989). Phenomenological research methods. In R. S. Valle \& S. Halling (Eds.), Existential-phenomenological perspectives in psychology (pp. 41-60). New York: Plenum. https://doi.org/10.1007/978-1-4615-6989-3_3

Prideaux, B., \& Cooper, C. (2003). Marketing and destination growth: A symbiotic relationship or simple coincidence? Journal of Vacation Marketing, 9(1), 35-51. https://doi.org/10.1177/135676670200900103

Qu, H., Kim, L. H., \& Im, H. H. (2011). A model of destination branding: Integrating the concepts of the branding and destination image. Tourism Management, 32(3), 465-476. https://doi.org/10.1016/j.tourman.2010.03.014

Sheehan, L., Ritchie, J. R. B., \& Hudson, S. (2007). The destination promotion triad: Understanding asymmetric stakeholder interdependencies among the city, hotels, and dmo. Journal of Travel Research. https://doi.org/10.1177/0047287507302383

United Nations World Tourism Organization. (2018). Retrieved from http://www2.unwto.org

Wang, Y. (2008). Collaborative destination marketing: Roles and strategies of convention and visitors bureaus. Journal of Vacation Marketing. 


\section{Macrothink}

Yuan, Y., Gretzel, U., \& Fesenmaier, D. (2006). The role of information technology use in American convention and visitors bureau. Journal of Tourism Management, 27, 326-341. https://doi.org/10.1016/j.tourman.2004.12.001

Zineldin, M. (2004). Co-optition: The organisation of the future. Marketing Intelligence and Planning, 22(7), 780-789. https://doi.org/10.1108/02634500410568600

\section{Copyright Disclaimer}

Copyright for this article is retained by the author(s), with first publication rights granted to the journal.

This is an open-access article distributed under the terms and conditions of the Creative Commons Attribution license (http://creativecommons.org/licenses/by/4.0/). 